\title{
What is the Impact of Covid-19 Pandemic on the RCH (Reproductive and Child Health) Programme in Rajasthan, because of nationwide lockdown (April 2020 to June 2020)?
}

Dr Piyush Kumar ( $\nabla$ drpiyush003@gmail.com )

Health Department, Government of Bihar https://orcid.org/0000-0001-9857-478X

Dr Habib Hasan Farooqui

IIPH-DELHI

\section{Research Article}

Keywords: Health, Decrease, Pandemic, Services/service, covid-19, sars-cov-2

Posted Date: August 30th, 2021

DOI: https://doi.org/10.21203/rs.3.rs-855882/v1

License: (c) (i) This work is licensed under a Creative Commons Attribution 4.0 International License. Read Full License 


\section{Abstract}

\section{Background:}

The proper, timely, adequate delivery of effective and high quality child health and reproductive (RCH) services is of greatest significance and utmost priority mainly because of situations erupting from current ongoing pandemic of covid-19 as well as other cofactors in state of Rajasthan, India. This significance and priority is particularly due to many factors such as huge as well as increasing population with limited qualified, skilled human resources

\section{Objective of study:}

The key objective is to find out effects of SARS-CoV-2/ Covid-19 pandemic on the Reproductive and Child Health Programme of Rajasthan in India over the 3 months after Lock down enforcement nationwide in March 2020.

\section{Settings \& Design:}

Different indicators of RCH programme i.e. immunisation, maternal and child health, family planning) for Rajasthan were observed, studied, collected and compared with previous year 2019for the period of April/May/June-2019 and 2020. The percent increase and downfall is observed, calculated, presented, from the available data to find out the status of delivery of essential RCH health services. The need assessed and percent of achievement of assessed need is also compared and future achievement projected as per achievement.

\section{Materials \& Methodology:}

To know the effect of pandemic era on RCH health programme of Rajasthan during the period from3 months after lock-down announced in the month of March 2020 i.e. April/May/June 2020 in Rajasthan the data observed, calculated and obtained from HMIS (Health Management Information System- of Ministry of Health and Family Welfare (MoHFW), Government of India for RC Health programme, (Reproductive and Child Health).

\section{Result:}

The results of data analysis for $\mathrm{RCH}$ services, functioning in the state of Rajasthan during the month during the period from April to June 2020 (during the period from lockdown) as compared to 2019 (no lockdown, for same duration suggest that the immunisation services were badly affected during the period from the lockdown period in 2020. It is possible that newborn children and the older ones have been not delivered proper immunisation services during the period from the lockdown as evident from the data observation-analysis.

\section{Conclusion:}

India and different states has launched several plans and strategies to deal with covid-19 pandemic. However this study report found that insufficient attention have been given to very essential services of RCH in Rajasthan as evident from the results of this study. The problems in the delivery of healthcare services should be dealt properly added with a proper update latest dynamic plan to carry on essential health delivery services even in pandemics and other situations of emergencies. The Rajasthan should develop an exclusive updated latest dynamic plan to deal with situations to guarantee delivery of very essential services such as RCH during the period from pandemics or any other natural calamities-emergencies.

The ongoing Covid-19 pandemic has disclosed the vulnerability of women and children's and at the same time teaches us about importance of equity in healthcare. The children and women's who are considered most vulnerable in emergencies and distress must have special supportive healthcare all the times especially during the period from pandemics-emergencies and other natural disasters.

\section{Chapter-1}

\section{1-INTRODUCTION}

The proper, timely, adequate delivery of effective and high quality RCH (Reproductive and Child Health) services is of greatest significance and utmost priority in situations erupting from current ongoing pandemic of covid-19 as well as other cofactors in state of Rajasthan, India. This significance and priority is particularly due to many factors such as huge as well as increasing population with limited qualified, skilled human resources ${ }^{1}$, vast area, difficult geographical locations, underdeveloped limited infrastructure as well as huge demand on healthcare system due to growing burden of NCD(noncommunicable) and $\mathrm{CD}$ (communicable diseases). The women and children's are considered as vulnerable group affected by hazards of such disaster conditions like covid-19 pandemic, hence this topic needs essential and special attention especially in current pandemic scenario 2020-21. India is second most populous nation after China and women's with children's constitutes a large section of current population. ${ }^{2}$

The current ongoing covid-19/ SARS-CoV-2 pandemic situation had presented a big challenge even for highly developed healthcare systems around the world. A sense of fear and insecurity gripped the whole world populations since 2019 due to pandemic and state of Rajasthan in India is not an exception. The limited underdeveloped healthcare system and poor health and other resources including transportation (ambulance services) manpower, infrastructure, etc. have been largely utilized to deal with the situation erupting from pandemic of SARS-CoV2. This one sided shifting of resources added with several other factors has incredible-sensational consequences on progress various health programmes such as RCH (reproductive and child health) running previously before this covid-19 pandemic era. Historically also the children's and women usually suffer more in such vulnerable situations like disasters and pandemics. One such finding is given by study done by Alice Reid on effects of 1918-1919 influenza pandemic he found thatyoung children and Infants are a more 
vulnerable group to different forms of communicable disease, and their relative mortality was also increased abnormally in pandemic, but talk about the young is mostly limited to mentions of school closures, or in the background of illness or mortality to whole families ${ }^{3}$.

Children's and pregnant mother are vulnerable groups due to their special health requirements and need more attention in disasters and pandemics due to special health and safety requirements such as ANC (antenatal care) and immunisation. After birth newborns are naturally immune to several diseases because they have antibodies acquired from their mothers in natural way. However, this acquired immunity declines slowly and gradually with time as baby grows up. Hence immunisation/vaccination is required to protect them from various vaccine preventable diseases(VPD) which are provided through universal immunization programmes (UIP-1985) to all children's in India (UNIVERSALIMMUNIZATIONPROGRAMME(UIP) ${ }^{4}$ - (See-Annexure-2).

The encouragement for child and maternal health, women up liftment have been done and addressed by many organisations of India and international repute for several years mentioning them as special vulnerable groups in times of disaster such as pandemic. The SARS-CoV-2 pandemic seems to disclose the limitations of health system to save above mentioned special groups as reported by WHO and other agencies expressing concerns over several issues related to women and children's ${ }^{5}$. As per current pandemic situation it is of special focus and requirement to have a separate health cadre of trained personals in the field of RCH to protect child and mother health hazards in special situations of disasters like covid-19 pandemics. It seems many protective and advantageous essential health services is not being provided in covid-19 era which may produce undesirable and detrimental effects at mass level in coming future. The World Health Organisation (WHO) have addressed these and many other concerns such as COVID-19 causes disruptions to child protection services in more than 100 countries, UNICEF(United Nations International Children's Emergency Fund) survey, millions more cases of female genital mutilation, unintended pregnancy, violence, child marriage, expected due to the COVID-19 pandemic ${ }^{6}$.

To recognize the real effect of covid-19 on child health, maternal, and family planning services provided under RCH programme the service utilisation data and other outcome indicators were analysed during month of April to June 2020 (lockdown phase) with non-lockdown phase of during the period from the same months in the previous year 2019. India was also under a lockdown period from $25^{\text {th }}$ march 2020 to $31^{\text {st }}$ may 2020 for a total period of 68 days during the period from which public transportation and many other services were stopped. The Ministry of Home Affairs, Government of India had issued order number 40-3/2020-D dated 24/03/20 regarding guidelines on suppression of covid-19 epidemic in the country stating in point number 6 That all transport services i.e. air, rail, roadways will remain suspended with few exceptions ${ }^{7}$. The HCWs (health care workers) not having their own vehicles to do routine duties added with high rate of covid-19 infection and deaths of HCWs also seems to affect healthcare delivery services.

\section{2-LITERATURE REVIEW}

$\mathrm{RCH}$ (Reproductive and child health) programme is a matter of concern for India even before independence due to several factors like socio-economic status, inequities, and lack of resources, infrastructure and many more. The practical problems in delivering these services are also faced at all levels. The RCH services are a matter of greatest concern in the ongoing pandemic era since December 2019 at global levels and particularly for countries like India. These concerns have been taken seriously by international organisations like WHO/UNICEF and alert regarding immunisation, ANC is being delivered at various levels as well as many scientific research is being carried out in this regard. In one such study as informed by WHO thatPregnancy with SARS-COV-2 are not as much likely than non- pregnant women with SARS-COV-2 to have symptoms, but more likely to need special-intensive care if severely ill, as per most recent research findings of the $B M J$ (British Medical Journal) on the risks of SARS-COV-2 for babies and pregnant women. The text literature suggests that pregnant women seen at the hospital with supposed or confirmed SARS-COV-2 are less likely to encounter a fever or muscle pain, but if they develop severe illness they are more likely to need ICU treatment than non-pregnant women with SARS-COV- $2^{9}$. The family planning programme is equally important as the population of India is increasing at a very fast pace which is increasing more demand on available resources. The key purpose of this review is to find out if there is convincing evidence that Rajasthan RCH programme is getting affected by SARS-CoV-2 pandemic. In the same statement mentioned before WHO, also stated that It is important to recognise the increased anxiety and stress caused by SARS-COV-2 which may be predominantly felt by children, pregnant women, their partners, in recent times-pregnant women, and families. Therefore healthcare workers have a big role in providing care to pregnant women in an appropriate and benevolent way.

The scope of this review is limited as more data and materials are required to complete it and there is also word limit for this report. As per NFHS-4(National Family Health Survey) survey data ${ }^{10}$ the total fertility rate (TFR) in Rajasthan is 2.4 children per woman, which is more than replacement level fertility (2.1). Fertility declined by only 0.4 children in the last 13 years period between NFHS-1 and NFHS-3, and has decreased further by 0.8 children in further 10 years period between NFHS-3 and NFHS-4.

Regarding pregnancy outcomes the NFHS-4 finding were that 91percent of previous pregnancies in the last five years preceding the survey resulted in a live birth, and the rest 9 percent ended in fetal wastage (miscarriage, or stillbirth, abortion,).and among these miscarriage was the most commonly found responsible for fetal wastage, about 7 percent of all pregnancies, and abortions lead to 2 percent fetal wastage. NFHS-4 survey also found that most of the abortions were done in the private health sector (59percent) and only 21 percent were done in the public health sector. Added to this report of NFHS-4 is that one-fourth of women having an abortion, reported to experience complications from the abortion. NFHS-4 survey found that awareness of contraception is almost universal in Rajasthan, except some methods are still less popular. 81 percent of recently married women know about injectables methods of contraception while 11 percent know about female condoms. Among all women, only 45 percent have knowledge of emergency contraception.

Regarding antenatal-care the NFHS-4 survey reported that among pregnant women's who gave birth in the last five years before the survey, more than 4/5th(83percent) received ANC for their last birth from a health professional (28percent from an auxiliary nurse midwife, and, lady health visitor (LHV), nurse, ormidwife55percent from a doctor). 14 percent did not get any ANC. Among mothers who gave birth in the last5years before the survey, more than 4/5th (85percent) registered the pregnancy for the most recent live birth. Among the registered pregnancies, 92 percent received MCP Card (Mother and Child Protection Card). Only 39 percent of mothers in Rajasthan acknowledged at least 4ANC visits for their last birth. Furthermore regarding delivery care the survey 
found that more than 4/5th of births (84percent) take place in a health facility (mostly a government facility) and 16 percent at home. The survey found that the percent of births in a health facility tripled in the 10 years period between NFHS-3 and NFHS-4, from 30 percent in NFHS-3 to 84 percent in NFHS-4. Institutional births are more common among women who have received an ANC check, women who are having their first birth, women with 12 or more years of schooling, urban women, and Sikh women. Survey also found that 84 percent of children in Rajasthan who were bom in the last five years were bom in a health facility.

Regarding immunization/vaccination the survey reports that more than half (55percent) of children between 12-23 months get all availablevaccinations against 6 (tuberculosis, diphtheria, Pertussis, tetanus, polio, and measles,) important childhood diseases before the survey. Most of the children are at least partially vaccinated; only 7 percent have not got any vaccinations at all. The survey also found that 89 percent of children have got a BCG vaccination. Added to this, very less children have received other basic vaccinations (65percent have got at least the recommended three doses of polio vaccine, 72 percent have got the three recommended doses of DPT vaccine, and 78percent have been vaccinated against measles). There is remarkable dropout between the 1 st and 3rd doses of DPT vaccine (from 86percent to 72percent) and polio vaccine (from 88percent to 65percent). One remarkable finding is that Coverage with all basic vaccinations is high for children whose mothers have completed 12 or more years of schooling.

\section{3-Rationale:}

One study published in the Lancet Global Health ${ }^{11}$ by Timothy Robertson et al. about the indirect effects of SARS-COV-2 on maternal and child mortality in LMICs with use of the Lives Saved Tool (LiST), found that reduced provision and use of reproductive, maternal, newborn, and child health-care services might substantially increase maternal and child deaths but this dissertation project is a totally different study incorporating three aspects viz. Maternal health, child health and family planning based on real-time data of an accredited source to find out impact of SARS-CoV-2 on RCH through output health indicators. This study furthermore, addresses the situations of Rajasthan, the constraints and limited access to information means that some major figures, such as for India and several other states and union territories as well as for longer periods data is not available-not been included. Finally, although several articles on this subject are available as seen in Google search, to evaluative the impact of SARS-CoV-2 on mother, child etc through studies using either qualitative or quantitative methods, to measure the effectiveness of RCH programs during the period fromSARS-CoV-2 is comparatively scarce. I have included relevant examples of these studies being done by myself for some other states and India17, 18,19,20,21, yet it can be said at the outset that the dearth of such studies needs to be redressed by the research community. Previous studies mentioned above have found a negative impact on health indicators of RCH programmes for few states and India which aroused my interest to know the impact of SARS-CoV-2 on other states. Rajasthan is the biggest state in India so I decided to do study on Rajasthan to know how RCH programme performance in such a big state during the period from the above mentioned period.

\section{Chapter-2}

\section{1-Study aim:}

$\mathrm{RCH}$ (Reproductive and child health) programme is a matter of concern for India even before independence due to several factors like socio-economic status, inequities, and lack of resources, infrastructure and many more. The key aim of this study is to understand the effect of covid19 pandemic era on RCH programme of Rajasthan for 3 months after lock down declared in the month of March 2020 i.e. April/May/June 2020 in Rajasthan.

\section{2-Study Objective:}

To know the real effect of SARS-CoV-2 on child health, maternal health, and family planning services provided under RCH programme the service utilisation data and other outcome indicators were analysed during the month of April to June 2020 (lockdown phase) with non-lockdown phase of during the period from the same months in the previous year 2019. India was also under a lockdown period from $25^{\text {th }}$ march 2020 to $31^{\text {st }}$ may 2020 for a total period of 68 days during the period from which public transportation and many other services were stopped. The Ministry of Home Affairs, Government of India had issued order number 40-3/2020-D dated 24/03/20 regarding guidelines on containment of SARS-CoV-2 epidemic in the country stating in point number 6 That all transport services i.e. air, rail, roadways will remain suspended with few exceptions

\section{Chapter-3-study Methods}

\section{1- Study Design}

The study design is retrospective mixed quantitative and qualitative analysis of the RCH programme of Rajasthan.

\section{2-Study setting and duration}

To know the impact of pandemic era on RCH programme of Rajasthan during 3 months after lock down declaration in the month of March 2020 i.e. April/May/June 2020 in Rajasthan. The data period under consideration is for the year 2019 and 2020, which was analysed to report several outcome indicators of interest.

\section{3-Sampling method}

The data obtained from HMIS (Health Management Information System) of Ministry of Health and Family Welfare (MoHFW), Government of India for RCH programmes (Reproductive and Child Health). The data analysis was done by Microsoft office software. The data is available for free distributions as mentioned by MoHFW-see excel table 2 below ${ }^{12}$.Differentoutcome indicators were taken into account to know the effect of SARS-CoV-2 Pandemic on delivery of health services to mother and child as well as family planning health services under the umbrella of RCH programme 


\section{4- Study Participants}

This study has not involved any human or animals in real or for experiments.

Inclusion criteria- Different indicators group of RCH programme (immunisation, maternal and child health, family planning) for Rajasthan during the month of April/May/June -2019 and 2020. (ANNEXURE -4)

Exclusion criteria- Different indicators group of RCH programme (immunisation, maternal and child health, family planning) for Rajasthan other than the month of April/May/June -2019 and 2020.

\section{5- Study tools and measurements}

The data analysis was done by Microsoft office software. The data is available for free distributions as mentioned by MoHFW-see excel table 2 below ${ }^{12}$. Different outcome indicators were taken into account to know the effect of SARS-CoV-2 Pandemic on provision of health services to mother and child as well as family planning health services under the umbrella of $\mathrm{RCH}$ programme.

Outcome- The study outcome is presented in the form of tables, graphs and literature.

Exposure- All the relevance to the study is listed in reference as well as data source is also documented.

\section{6- Data collection tool}

The data obtained from HMIS (ANNEXURE -3-Table 2) of Ministry of Health and Family Welfare (MoHFW), Government of India for RCH programmes (Reproductive and Child Health) with the help of internet. The data analysis was done by Microsoft office software. For understanding impact on immunisation, the output indicators considered were immunisation data related to -(1) TETANUS TOXOID (TT16), (2) VITAMIN A (1 ${ }^{\text {st }}$ DOSE), (3) VITAMIN A (5 $5^{\text {th }}$ DOSE), (4) VITAMIN A (9 ${ }^{\text {th }}$ DOSE) (5) BCG-BACILLUS CALMETTE GUERIN, (6) PENTA 3+DPT 3, (7) DT (2 ${ }^{\text {ND }}$ DOSE) OR DPT-5, (8) MEASLES + MR, (9) POLIO (OPV 3), (10) TETANUS TOXOID (TT10),. For maternal health and family planning outcome indicators considered were- (1) ANC, (2) HOME DELIEVERIES, (3)INSTITUTIONAL DELIEVERIES, (4)CONDOM USER, (5) ORAL PILL USER, (6) IUD INSERTION, (7)STERILISATION, (8) TUBECTOMY, (9) VASECTOMY

\section{7-Study size, Place and Population}

Rajasthan is the biggest state of India with a population of 06.86 crores, as per census 2011, density 200/square kilometre, with some difficult geographic locations. The total numbers of districts are 33 with division into sub districts. The total child population as per 2011 census was (0-6 years) 106.5 lakh and the total female population was 329.97lakh whereas males were 355.5 lakh in number. The population growth as per 2011 census was 21.31 percent and state have 5.66 percent of total population of Rajasthan with literacy rate of 66.11 percent. The projected population is 08.07 crores. The total married women as per 2011 census were 187.51 lakh with number of women with 7 plus child born was 15.57 lakh. Rajasthan is among the top 10 most populous states as well as growth rate ${ }^{8}$.

\section{8-Data collection process (Settings and Design):}

Different indicators group (immunisation, maternal and child health, family planning) of RCH programme for Rajasthan were taken into consideration for the study and data collected and compared from previous year during the month of April/May/June -2019 and 2020.

\section{9- Data analysis}

The percent increase and decline is calculated from the collected and available data to know the status of provision of important and essential health services. The need assessed and percent of achievement of assessed need is also compared and future achievement projected as per achievement. The data analysis was done by Microsoft office software. The data is also shown in tabulated as well as graphical form for ease of understanding. All the data obtained were analysed using Microsoft office software.

\section{Chapter-4}

Ethical Consideration- The ethical committee have been requested to provide clearance over the ethical issue as this study has not involved any human or animals in real or for experiments.

\section{Chapter-5}

\section{5-RESULTS}

Antenatal care is very much essential for safeguarding the health of women and their unborn children. ANC provide with preventive health care as well as pregnant women know from trained healthcare personnel regarding good healthy measures during the period from pregnancy, and better knowledge of danger signs during this period from pregnancy and childbirth, and receive social, sympathetic and psychological care at this vital time in their lives. The ANC services and institutional deliveries are significant to assess the condition of maternal care. Although home deliveries declined during this period of observation but at the same time the institutional deliveries also decreased which are matters of great concern. 
The data analysis results regarding RCH services performance in the state of Rajasthan during the period from the month of April to June 2020 (during the period from lockdown) as compared to previous year 2019(no lockdown) for same months suggest that the immunisation services had been adversely affected during the period from the lockdown period in 2020. It is evident from the findings of the study that not only newborn children but also the older ones have not received basic immunisation services.

Due to increasing population there is a general trend of increase in need assessed as well as numbers achieved every year in all above indicators every year. The decline in achievement of such important indicators clearly signifies that SARS-CoV-2 pandemic have a negative effect on provision of RC health services such as maternal and child health. The role of family planning is very important in context of Rajasthan with increasing population and scanty natural resources. All family planning programmes reduced from previous year timeline for the same months indicating that the population control strategy of Rajasthan also suffered during this period.

\section{1- Immunisation coverage for 2019 and 2020 during the month of April to June (Rajasthan)}

Table number 1 shows that as compared to previous year 2019 data- For BCG immunisation there is a decline of 14.5percentin 2020, Since BCG is given at birth it seems that either less number of children's is born during the period from this period or many have not received it, For Penta3+DPT3 the decline was 32.4percent in 2020 ,For DT or DPT5 the decline was 34.1percent in 2020,For Measles+MR the decline was 10.7percent in 2020,For OPV3 the decline was 32.4percent in 2020,For TT10 the decline was 40.7percent in 2020,For TT16 the decline was 43.9percent in 2020,For vitamin A which is given from 9 months of age $1^{\text {st }}$ dose declined by 9.9 percent in 2020, Vitamin A $2^{\text {nd }}$ to $9^{\text {th }}$ dose starts from 16 months of age (one dose every 6 month),Vitamin A $5^{\text {th }}$ dose declined by 61.6percent in 2020, Vitamin A $9^{\text {th }}$ dose declined by 77.4 percent in 2020 . Here it is important to mention that vitamins A and OPV both are given orally. OPV 3 is given at the age of 14 weeks whereas vitamin A is started from 9 month onwards. This observation suggests that the immunisation coverage for children of all ages declined in 2020 during April/May/June as compared to 2019 when the pandemic was not in existence.

Table 1- comparison of immunisation coverage during 2019 and 2020 during the month of April to June (Rajasthan)

\begin{tabular}{|c|c|c|c|c|}
\hline IMMUNISATION & $\begin{array}{l}\text { ITEM } \\
\text { CODE }\end{array}$ & $\begin{array}{l}\text { NUMBERS OF ACHIEVEMENTDURING } \\
\text { THE PERIOD FROM APRIL TO JUNE } \\
-2020-21\end{array}$ & $\begin{array}{l}\text { NUMBERS OF ACHIEVEMENTDURING } \\
\text { THE PERIOD FROM APRIL TO JUNE } \\
-2019-20\end{array}$ & $\begin{array}{l}\text { INCREASE/DECREASE IN } \\
2020 \text { COMPARED TO } 2019 \\
\text { PERCENT }\end{array}$ \\
\hline $\begin{array}{l}\text { BCG-BACILLUS } \\
\text { CALMETTE } \\
\text { GUERIN }\end{array}$ & 9.1 .2 & 263,111 & 307,840 & DECREASE 14.5PERCENT \\
\hline PENTA 3+DPT 3 & $9.1 .5,9.1 .8$ & 215,897 & 319,423 & DECREASE 32.4PERCENT \\
\hline $\begin{array}{l}\text { DT (2ND DOSE) } \\
\text { OR DPT-5 }\end{array}$ & 9.5 .2 & 110,328 & 167,383 & DECREASE 34.1PERCENT \\
\hline MEASLES + MR & $9.2 .1,9.2 .2$ & 313,047 & 350,584 & DECREASE 10.7PERCENT \\
\hline POLIO (OPV 3) & 9.1 .12 & 216,018 & 319,713 & DECREASE 32.4PERCENT \\
\hline $\begin{array}{l}\text { TETANUS } \\
\text { TOXOID (TT10) }\end{array}$ & 9.5 .3 & 75,961 & 128,091 & DECREASE 40.7PERCENT \\
\hline $\begin{array}{l}\text { TETANUS } \\
\text { TOXOID (TT16) }\end{array}$ & 9.5 .4 & 65,078 & 115,958 & DECREASE 43.9PERCENT \\
\hline $\begin{array}{l}\text { VITAMIN A (1ST } \\
\text { DOSE) }\end{array}$ & 9.8 .1 & 306,922 & 340,687 & DECREASE 9.9 PERCENT \\
\hline VITAMIN A (5TH) & 9.8 .2 & 122,037 & 318,123 & DECREASE 61.6PERCENT \\
\hline VITAMIN A (9TH) & 9.8 .3 & 66,533 & 293,822 & DECREASE 77.4 PERCENT \\
\hline
\end{tabular}

\section{2- Needs assessment and achievement comparison for Immunisation}

\section{(ANNEXURE -7-Chart 3ANNEXURE -6-Chart 2ANNEXURE -5-Chart 1)}

Table number 2 shows that as compared to previous year 2019 data- The need assessed for BCG (BACILLUS CALMETTE GUERIN) in 2020-21 increased as compared to 2019-20(1822630-1789690) by 32940 numbers. The achievement of-need assessed in 2020-21 during the period from April to June (263,111/14.4percent)decreased as compared to 2019-20(307840/17.2 percent) by44729 numbers and 2.8percent; the need assessed for PENTA $3+$ DPT 3 in 2020-21 increased as compared to 2019-20(1822630-1789690) by 32940 numbers. The achievement of-need assessed in 2020-21 during the period from April to June (215897/11.8percent) decreased as compared to 2019-20(319423/17.8 percent) by103526 numbers and 6percent; the need assessed for DT (2 ${ }^{\text {ND }}$ DOSE) OR DPT-5 in 2020-21 increased as compared to 2019-20(1725000-1688500) by 36500 numbers. The achievement of-need assessed in 2020-21 during the period from April to June (110328/06.4percent) decreased as compared to 2019-20(167383/09.9 percent) by 57055 numbers and 3.5 percent; 
The need assessed for MEASLES + MR in 2020-21 increased as compared to 2019-20(1822630-1789690) by 32940 numbers. The achievement of-need assessed in 2020-21 during the period from April to June (313047/17.2percent) decreased as compared to 2019-20(350584/19.6 percent) by37537 numbers and 2.4percent; the need assessed for POLIO (OPV 3) in 2020-21 increased as compared to 2019-20(1822630-1789690) by 32940 numbers. The achievement of-need assessed in 2020-21 during the period from April to June (216018/11.9percent) decreased as compared to 2019-20(319713/17.9 percent) by 103695 numbers and 6percent; the need assessed for TETANUS TOXOID (TT10) in 2020-21 increased as compared to 2019-20(1615140-1581000) by 34140 numbers. The achievement of-need assessed in 2020-21 during the period from April to June (75961/04.7percent) decreased as compared to 201920(128091/08.1 percent) by52130 numbers and 3.4percent;theneed assessed for TETANUS TOXOID (TT16) in 2020-21 increased as compared to 201920(1863310-1823900) by 39410 numbers. The achievement of-need assessed in 2020-21 during the period from April to June (65078/03.5percent) decreased as compared to 2019-20(115958/06.4percent) by50880 numbers and 2.9percent; the need assessed for VITAMIN A (1 ST DOSE) in 2020-21 increased as compared to 2019-20(1822630-1789690) by 32940 numbers. The achievement of-need assessed in 2020-21 during the period from April to June (306922/16.8percent) decreased as compared to 2019-20(340687/19.0 percent) by33765 numbers and 2.2percent; the need assessed for VITAMIN A (5 DOSE) in 2020-21 increased as compared to 2019-20(1780150-1742500) by 37650 numbers. The achievement of-need assessed in $2020-21$ during the period from April to June (122037/06.9percent) decreased as compared to 2019-20(318123/18.3percent) by 196086 numbers and 11.4 percent; the need assessed for VITAMIN A ( $9^{\text {th }}$ DOSE) in 2020-21 increased as compared to 2019-20(1725000-1688500) by 36500 numbers. The achievement of-need assessed in $2020-21$ during the period from April to June (66533/03.9percent) decreased as compared to 2019-20(293,822/17.4percent) by227289 numbers and 13.5percent;

Table 2- Needs assessment and achievement comparison for Immunisation

\begin{tabular}{|c|c|c|c|c|c|c|c|}
\hline \multirow[t]{2}{*}{ IMMUNISATION } & \multirow[t]{2}{*}{$\begin{array}{l}\text { ITEM } \\
\text { CODE }\end{array}$} & \multirow{2}{*}{$\begin{array}{l}\text { NEED } \\
\text { ASSESSED } \\
2020-21\end{array}$} & \multirow{2}{*}{$\begin{array}{l}\text { ACHIEVEMENT } \\
\text { OF NEED } \\
\text { ASSESSED } \\
\text { 2020-21 } \\
\text { DURING THE } \\
\text { PERIOD FROM } \\
\text { APRIL TO } \\
\text { JUNE }\end{array}$} & \multirow{2}{*}{$\begin{array}{l}\text { PERCENT ACHIEVEMENT OF } \\
\text { NEED ASSESSED DURING } \\
\text { THE PERIOD FROM APRIL TO } \\
\text { JUNE 2020-21 }\end{array}$} & \multirow{2}{*}{$\begin{array}{l}\text { NEED } \\
\text { ASSESSED } \\
2019-20\end{array}$} & \multirow{2}{*}{$\begin{array}{l}\text { ACHIEVEMENT } \\
\text { OF-NEED } \\
\text { ASSESSED } \\
2019-20 \\
\text { DURING THE } \\
\text { PERIOD FROM } \\
\text { APRIL TO } \\
\text { JUNE }\end{array}$} & \multirow{2}{*}{$\begin{array}{l}\text { PERCENT } \\
\text { ACHIEVEMENT OF } \\
\text { NEED ASSESSED } \\
\text { DURING THE PERIOD } \\
\text { FROM APRIL TO } \\
\text { JUNE 2019-20 }\end{array}$} \\
\hline & & & & & & & \\
\hline $\begin{array}{l}\text { BCG-BACILLUS } \\
\text { CALMETTE } \\
\text { GUERIN }\end{array}$ & 9.1 .2 & 1822630 & 263,111 & 14.4 & 1789690 & 307,840 & 17.2 \\
\hline $\begin{array}{l}\text { PENTA 3+DPT } \\
3\end{array}$ & $9.1 .5,9.1 .8$ & 1822630 & 215,897 & 11.8 & 1789690 & 319,423 & 17.8 \\
\hline $\begin{array}{l}\text { DT ( } 2^{\mathrm{ND}} \text { DOSE) } \\
\text { OR DPT-5 }\end{array}$ & 9.5 .2 & 1725000 & 110,328 & 6.4 & 1688500 & 167,383 & 9.9 \\
\hline MEASLES + MR & $9.2 .1,9.2 .2$ & 1822630 & 313,047 & 17.2 & 1789690 & 350,584 & 19.6 \\
\hline POLIO (OPV 3) & 9.1 .12 & 1822630 & 216,018 & 11.9 & 1789690 & 319,713 & 17.9 \\
\hline $\begin{array}{l}\text { TETANUS } \\
\text { TOXOID (TT10) }\end{array}$ & 9.5 .3 & 1615140 & 75,961 & 4.7 & 1581000 & 128,091 & 8.1 \\
\hline $\begin{array}{l}\text { TETANUS } \\
\text { TOXOID (TT16) }\end{array}$ & 9.5 .4 & 1863310 & 65,078 & 3.5 & 1823900 & 115,958 & 6.4 \\
\hline $\begin{array}{l}\text { VITAMIN A (1 }{ }^{\text {ST }} \\
\text { DOSE) }\end{array}$ & 9.8 .1 & 1822630 & 306,922 & 16.8 & 1789690 & 340,687 & 19.0 \\
\hline $\begin{array}{l}\text { VITAMIN A } \\
\left(5^{T H}\right)\end{array}$ & 9.8 .2 & 1780150 & 122,037 & 6.9 & 1742500 & 318,123 & 18.3 \\
\hline $\begin{array}{l}\text { VITAMIN A } \\
\left(9^{\mathrm{TH}}\right)\end{array}$ & 9.8 .3 & 1725000 & 66,533 & 3.9 & 1688500 & 293,822 & 17.4 \\
\hline
\end{tabular}

\section{3-Maternal health coverage during 2019-20 and 2020-21 during the month of April to June (Rajasthan)}

Regarding Maternal health coverage during 2019and 2020 during the month of April to June (Rajasthan),Table 3 analyses shows that need assessed for ANC in 2020-21 was 2066780 whereas the numbers of achievement during the period from April to June 2020-21 was 445804 which was 21.6 percent of need assessed. In comparison need assessed for ANC in 2019-20 was 2031500 whereas the numbers of achievement during the period from April to June 2019-20 was 461,360 which was 22.7 percent of need assessed, the percent decrease in numbers of achievement during the period from $2020-21$ compared to $2019-20$ found a decrease of 3.4percent in 2020-21; The need assessed for home deliveries in 2020-21 is not available whereas the numbers of achievement during the period from April to June 2020-21 was 6489, In comparison need assessed for ANC in 2019-20 is also not available whereas the numbers of achievement during the period from April to June 2019-20 was 5588. The percent increase in numbers of achievement during the period from 2020-21 compared to 2019-20 found an increase of 16.1percent in 2020-21; The need assessed for institutional deliveries in 2020-21 was 1892660 whereas the numbers of achievement during the period from April to June 2020-21 was 257123 which was 13.6 percent of need assessed. In comparison need assessed in $2019-20$ were 1860380 whereas the numbers of achievement during the period from April to June 2019-20 was 299624 which were 16.1 percent of need assessed. The percent decrease in numbers of achievement during the period from 2020-21 compared to 2019-20 found a decrease of 14.2percent in 2020-21. 
Table 3 - Maternal health coverage during 2019-20and 2020-21during the month of April to June (Rajasthan) (ANNEXURE -11-Chart 6, ANNEXURE -10-Chart 5, ANNEXURE -9-Chart 4)

\begin{tabular}{|c|c|c|c|c|c|c|c|c|}
\hline $\begin{array}{l}\text { MATERNAL } \\
\text { HEALTH }\end{array}$ & ITEM CODE & $\begin{array}{l}\text { NUMBERS OF } \\
\text { ACHIEVEMENTDURING } \\
\text { THE PERIOD FROM } \\
\text { APRIL TO JUNE 2020- } \\
21\end{array}$ & $\begin{array}{l}\text { NEED } \\
\text { ASSESSED } \\
2020-21\end{array}$ & $\begin{array}{l}\text { PERCENT } \\
\text { OF NEED } \\
\text { ACHIEVED } \\
\text { DURING } \\
\text { THE } \\
\text { PERIOD } \\
\text { FROM } \\
\text { APRIL TO } \\
\text { JUNE } \\
2020-21\end{array}$ & $\begin{array}{l}\text { NUMBERS OF } \\
\text { ACHIEVEMENTDURING } \\
\text { THE PERIOD FROM } \\
\text { APRIL TO JUNE -2019- } \\
20\end{array}$ & $\begin{array}{l}\text { NEED } \\
\text { ASSESSED } \\
2019-20\end{array}$ & $\begin{array}{l}\text { PERCENT OF } \\
\text { NEED } \\
\text { ACHIEVED } \\
\text { DURING THE } \\
\text { PERIOD FROM } \\
\text { APRIL TO } \\
\text { JUNE 2019-20 }\end{array}$ & $\begin{array}{l}\text { PER } \\
\text { INCF } \\
\text { IN ( } \\
\text { ACH } \\
21 \mathrm{C} \\
2011\end{array}$ \\
\hline ANC & 1.1 & 445,804 & 2066780 & $\begin{array}{l}21.6 \\
\text { PERCENT }\end{array}$ & 461,360 & 2031500 & 22.7 PERCENT & $\begin{array}{l}\text { DEC } \\
\text { PER }\end{array}$ \\
\hline $\begin{array}{l}\text { MATERNAL } \\
\text { HEALTH HOME } \\
\text { DELIEVERIES }\end{array}$ & 2.1.1.A,2.1.1.B & 6,489 & & & 5,588 & & & $\begin{array}{l}\text { INCF } \\
\text { PER }\end{array}$ \\
\hline $\begin{array}{l}\text { MATERNAL } \\
\text { HEALTH } \\
\text { INSTITUTIONAL } \\
\text { DELIEVERIES }\end{array}$ & 2.2 & 257,123 & 1892660 & $\begin{array}{l}13.6 \\
\text { PERCENT }\end{array}$ & 299,624 & 1860380 & $\begin{array}{l}16.1 \\
\text { PERCENT }\end{array}$ & $\begin{array}{l}\text { DEC } \\
14.2\end{array}$ \\
\hline
\end{tabular}

\section{4-Family planning coverage comparison for 2019 and 2020 during the month of April to June (Rajasthan)-(ANNEXURE -13-Chart8\&ANNEXURE -12-Chart7)}

Regarding Family planning coverage comparison for 2019 and 2020 during the month of April to June (Rajasthan), Table 4 analyses shows that- the need assessed for condom user in 2020-21 was 8995120 whereas need assessed for condom user in 2019-20 was 8740800 , an increase of 254320 is seen in 2020-21; the numbers of achievement during the period from April to June 2020-21 was 419235 which was 04.7 percent of need assessed whereas the numbers of achievement during the period from April to June 2019-20 was 449495 which was 05.1 percent of need assessed. The Percent decrease in numbers of achievement during the period from April to June 2020-21 compared to 2019-20 found a decrease of 06.7percent in 2020-21. The need assessed for oral pill users in 2020-21 was 8995120 whereas need assessed for oral pill user in 2019-20 was 8740800, an increase of 254320 is seen in 2020-21; the numbers of achievement during the period from April to June 2020-21 was 235,582 which was 02.6 percent of need assessed whereas the numbers of achievement during the period from April to June 2019-20 was 252,298 which was 02.9 percent of need assessed. The percent decrease in numbers of achievement during the period from 2020-21 compared to 2019-20 found a decrease of 06.6percent in 2020-21. The need assessed for IUD insertion in 202021 was $\mathbf{8 9 9 5 1 2 0}$ whereas in comparison need assessed for IUD insertion in 2019-20 was $\mathbf{8 7 4 0 8 0 0}$, an increase of 254320 is seen in $2020-21$; the numbers of achievement during the period from April to June 2020-21 was $\mathbf{8 9 , 5 3 9}$ which was 01.0 percent of need assessed whereas the numbers of achievement during the period from April to June 2019-20 was 124,786 which were 01.4 percent of need assessed. The percent decrease in numbers of achievement during the period from April to June 2020-21 compared to 2019-20 found a decrease of 28.2percent in 2020-21.

The need assessed for sterilisation (ANNEXURE -14-Chart9) in 2020-21 was 15220170 whereas in comparison need assessed for sterilisation in 2019-20 was 14789800, an increase of 430370 is seen in 2020-21; the numbers of achievement during the period from April to June 2020-21 was 13698 which was 0.1 percent of need assessed whereas the numbers of achievement during the period from April to June 2019-20 was 61399 which were 0.4 percent of need assessed. The percent decrease in numbers of achievement during the period from April to June 2020-21 compared to $2019-20$ found a decrease of 77.7percent in 2020-21.The need assessed for tubectomy in 2020-21 was 15220170 whereas in comparison need assessed for tubectomy in 2019-20 was 14789800, an increase of 430370 is seen in 2020-21; the numbers of achievement during the period from April to June $2020-21$ was 13561 which was 0.1 percent of need assessed whereas the numbers of achievement during the period from April to June $2019-20$ was 60768 which were 0.4 percent of need assessed. The percent decrease in numbers of achievement during the period from 2020-21 compared to 2019-20 found a decrease of 77.7percent in 202021. The need assessed for vasectomy in 2020-21 was 15220170 whereas in comparison need assessed for vasectomy in 2019-20 was 14789800, an increase of 430370 is seen in 2020-21,the numbers of achievement during the period from April to June 2020-21 was 137 which was 0.0 percent of need assessed whereas the numbers of achievement during the period from April to June 2019-20 was 631 which were 0.0 percent of need assessed. The percent decrease in numbers of achievement during the period from 2020-21 compared to 2019-20 found a decrease of 78.3percent in 2020-21.

Table 4 - Family planning coverage Comparison for 2019 and 2020 during the period from the month of April to June (Rajasthan) 


\begin{tabular}{|c|c|c|c|c|c|c|c|c|}
\hline $\begin{array}{l}\text { FAMILY } \\
\text { PLANNING }\end{array}$ & ITEM CODE & $\begin{array}{l}\text { NUMBERS OF } \\
\text { ACHIEVEMENT } \\
\text { APRIL TO } \\
\text { JUNE 2020-21 }\end{array}$ & $\begin{array}{l}\text { NEED } \\
\text { ASSESSED } \\
2020-21\end{array}$ & $\begin{array}{l}\text { PERCENT OF } \\
\text { NEED } \\
\text { ACHIEVED } \\
\text { DURING THE } \\
\text { PERIOD FROM } \\
\text { APRIL TO } \\
\text { JUNE 2020-21 }\end{array}$ & $\begin{array}{l}\text { NUMBERS OF } \\
\text { ACHIEVEMENT } \\
\text { APRIL TO } \\
\text { JUNE 2019-20 }\end{array}$ & $\begin{array}{l}\text { NEED } \\
\text { ASSESSED } \\
2019-20\end{array}$ & $\begin{array}{l}\text { PERCENT } \\
\text { OF NEED } \\
\text { ACHIEVED } \\
\text { DURING } \\
\text { THE PERIOD } \\
\text { FROM } \\
\text { APRIL TO } \\
\text { JUNE 2019- } \\
20\end{array}$ & $\begin{array}{l}\text { PERCENT } \\
\text { INCREASE } \\
\text { /DECREASE } \\
\text { IN NUMBERS } \\
\text { OF } \\
\text { ACHIEVEMENT } \\
2020-21 \\
\text { COMPARED } \\
\text { TO 2019-20 }\end{array}$ \\
\hline CONDOM USER & 8.13 & 419,235 & 8995120 & 4.7 & 449,495 & 8740800 & 5.1 & $\begin{array}{l}\text { DECREASE } \\
\text { 6.7PERCENT }\end{array}$ \\
\hline $\begin{array}{l}\text { ORAL PILL } \\
\text { USER }\end{array}$ & $8.12,8.14$ & 235,582 & 8995120 & 2.6 & 252,298 & 8740800 & 2.9 & $\begin{array}{l}\text { DECREASE } \\
\text { 6.6PERCENT }\end{array}$ \\
\hline IUD INSERTION & $8.3,8.4,8.5$ & 89,539 & 8995120 & 1.0 & 124,786 & 8740800 & 1.4 & $\begin{array}{l}\text { DECREASE } \\
\text { 28.2PERCENT }\end{array}$ \\
\hline STERILISATION & $\begin{array}{l}\text { 8.2.1,8.2.2, } \\
8.2 \cdot 3,8 \cdot 2 \cdot 4,8.1 .1\end{array}$ & 13,698 & 15220170 & 0.1 & 61,399 & 14789800 & 0.4 & $\begin{array}{l}\text { DECREASE } \\
\text { 77.7PERCENT }\end{array}$ \\
\hline TUBECTOMY & $\begin{array}{l}\text { 8.2.1,8.2.2, } \\
8.2 .3,8.2 .4\end{array}$ & 13,561 & 15220170 & 0.1 & 60,768 & 14789800 & 0.4 & $\begin{array}{l}\text { DECREASE } \\
\text { 77.7PERCENT }\end{array}$ \\
\hline VASECTOMY & 8.1 .1 & 137 & 15220170 & 0.0 & 631 & 14789800 & 0.0 & $\begin{array}{l}\text { DECREASE } \\
\text { 78.3PERCENT }\end{array}$ \\
\hline
\end{tabular}

Note-Sterilisation includes both tubectomy and vasectomy but need to be shown separately as per international guidelines and moreover the two processes are also different, tubectomy is done for female sterilisation whereas vasectomy is done for male sterilisation. The percentage of achievement of need assessed is different from the percentage comparison of numbers of achievement during the period from April to June of two financial years.

\section{Chapter-6}

\section{DISCUSSION}

The observation, study, calculation and analysis of data obtained from HMIS (health management information system), Ministry of Health and Family Welfare website for RCH programme in Rajasthan shows that the lock down period and initial early phase of SARS-CoV-2 pandemic had a negative effect on the provision of RCH health services as detailed in results above. Besides the pandemic Rajasthan is also having lack of resources, skilled manpower poor infrastructure as well as positive deviance at community level ${ }^{13}$. These are the hindrances in the provision of RCH services beside the epidemic.

$\mathrm{RCH}$ (reproductive and child health) service provision is always a priority and great concern for populous nations particularly India with high levels of fertility. During the period from theSARS-CoV-2 pandemic era it's more challenging to deliver such essential services due to fear factors at community as well as health personal level. Fall in rate of immunisation can lead to emergence of diseases which is being controlled by immunisation programmes. If an unvaccinated child is open to the elements to disease microorganisms, the child's body may not be physically powerful as much as necessary to fight the disease. Before the discovery and invention of vaccines, several children's died from diseases that vaccines now put off; such examples are whooping cough, measles, and polio. Though same microorganisms are present today, but since babies are cosseted by vaccines, we don't see these diseases nearly as frequently. Immunizing particularly children's also helps to guard the health of our community, in particular those who cannot be immunized (children who are too young to be vaccinated, or those who can't receive assured vaccines for medicinal/therapeutic reasons), and the little percentage of children who don't act in response to a particular vaccine. Vaccine-preventable diseases have an expensive brunt, resulting in hospital visits, hospitalizations, and early premature morbidity and mortality. Sick children can also cause parents to lose time from work ${ }^{14}$.

Limited, insufficient and under quality ANC services will pose a threat to maternal as well as foetus life. Good quality antenatal care also provides pregnant women with micronutrient supplementation, management for hypertension to inhibit eclampsia, as well as immunization against tetanus. Antenatal care makes available HIV testing and provides drugs to prevent mother-to-child transmission of HIV in pregnancy, childbirth, or breastfeeding (through breast milk). In malaria endemic zones, health personnel can make available pregnant women with drugs and insecticide-treated mosquito nets (ITNs) to help put off this devastating and sometimes deadly disease ${ }^{15}$.

The insufficiency in family planning coverage will add more to burden of population explosion putting more pressure on available resources depletion. Women should be encouraged for making the choice, to take decision about the number and spacing of their conception. Family planning can help women protect their health and fertility and also in improving the quality of their own and family lives. Family planning also help in getting better children's health and ensuring access to enough food, clothing, housing, and educational opportunities. Family planning achieves these improvements in health and value of life in a better way compared with fund investments in most other health and social interventions. Committing human and financial assets for improving family 
planning services will get better health and well-being of women and children, and at the same time it will also prop up efforts to achieve a sustainable global population $^{16}$.

All states and union territories of India have enforced various different strategies but it appears to be not totally effective to get good results on RCHealth programme. The Government of Rajasthan should consider taking help of local intellectual people and communities as well as increasing skilled human resources working to safeguard maternal and child health in situations of distress-emergency such as SARS-CoV-2 pandemic. For this the barriers in provision of RCH services like less number of skilled doctors, nurses, other resources should be reduced-rectified and promoters of RCH programme like health promotion activities creating awareness of benefits and addressing misbelieves and questions needs to be considered by policy-decision makers to achieve the maximum output from efforts and available resources.

Observations and analysis based on HMIS data from Bihar, Uttar Pradesh, Andhra Pradesh and India has also been conducted and submitted for peer reviewed publications which is available online for further reference. ${ }^{17,18,19,20,21}$

The topic is of prime concern particularly for LMICs (low and middle income countries).Some researchers have used one modern LiST (lives saved tool) method to calculate the impact. One such study done by Timothy Roberton et al, found the indirect impacts of the SARS-COV-2 pandemic on maternal and child mortality in LMICs in which the health service coverage of essential maternal and child health interventions is reduced by $9 \cdot 8-51 \cdot 9 \%$ and the prevalence of wasting is up by $10-50 \% 22$.

\section{Chapter-7}

Limitations of the Study-The data although collected from an accredited source may have some errors of reporting and human error etc. Moreover it's stated by government that they use to refresh the data if some corrections are required. If the data is changed by the government which is usually rare the results will change accordingly.

\section{Chapter-8}

CONCLUSION: India and different states has launched several plans and strategies to deal with SARS-CoV-2 pandemic. However this study report found that insufficient attention have been given to very essential services of RCH in Rajasthan as evident from the results of this study. The problems in the provision of healthcare services should be dealt properly added with a proper update latest dynamic plan to carry on essential health delivery services even in pandemics and other situations of emergencies. The Rajasthan should develop an exclusive updated latest dynamic plan to deal with situations to guarantee provision of very essential services such as RCH during the period from pandemics or any other natural calamities-emergencies.

The ongoing SARS-CoV-2 pandemic has disclosed the vulnerability of women and children's and at the same time teaches us about importance of equity in healthcare. The children and women's who are considered most vulnerable in emergencies and distress must have special supportive healthcare all the times especially during the period from pandemics-emergencies and other natural disasters.

India is the second most populous country in the world after china. To control the ongoing population explosion including Rajasthan all states should have a robust population control strategy to working in all the conditions of emergency as well as in normal conditions.

Data availability - The data is available as supplement as well as at the following web serviceshttps://www.mohfw.gov.in/index.html

\section{Declarations}

-This paper has not been previously published and is not currently under consideration by another

journal. The document is Microsoft word with English (India) language \& 8555 words Total.

- Ethics approval and consent to participate: Not applicable. This study has not involved any human

or animals in real or for experiments.

-Consent for publication: Not applicable

-Availability of data and materials: The data \& materials for study are mentioned in article and

available as reference.

-Conflicts of Interest/ Competing Interest: There are no conflicts / competing of interest

- Funding-Self sponsored. No aid taken from individual or agency etc.

- Authors' contributions: The whole work is solely done and verified by the Author - Dr Piyush Kumar,

M.B.B.S. - Sri Krishna Medical College, EMOC- General Medical Officer- Bihar Health ServicesGovernment of Bihar, India, under supervision of Dr Habib Hasan Farooqi from IIPH-Delhi. 
- Acknowledgements- I am thankful to Advocate Anupama my wife and my daughters Aathmika-Atheeva for cooperation.

- Author information: The author is currently working as Senior medical officer for the government of

Bihar.

-Financial Support \& sponsorship: Nil

-Author contact information

1 Department of Health, Government of Bihar, MOBILE - +919955301119/+917677833752,

Email drpiyush003@gmail.com

\section{Abbreviations}

RCH- reproductive and child health, HCWs-health care workers, ANC- antenatal care, BMJ-British Medical Journal, VPD-vaccine preventable diseases. NFHSNational Family Health Survey, WHO-World Health Organization, TFR- total fertility rate, UNICEF- United Nations International Children's Emergency Fund, ANM- auxiliary nurse midwife, LHV- lady health visitor, MCP- Mother and Child Protection, LMICs- low-income and middle-income countries, LiST- Lives Saved Tool, HMIS- Health Management Information System, MoHFW- Ministry of Health and Family Welfare, BCG-bacillus calmette Guerin, DPT- Diphtheria Pertussis Tetanus, DT- Diphtheria Tetanus, MR- Measles Rubella, TT- Tetanus Toxoid, IUD-Intrauterine Device, OPV- Oral Polio Vaccine,

\section{References}

1. Karan A, Negandhi H, Hussain S, Zapata T, Mairembam D, De Graeve H, Buchan J, Zodpey S. Size, composition and distribution of health workforce in India: why, and where to invest? Hum Resource Health. 2021 Mar 22; 19(1):39. Doi: 10.1186/s12960-021-00575-2. PMID: 33752675; PMCID: PMC7983088.

2. Kumar Dr. Piyush. What Impact Have SARS-CoV-2/Covid-19 Pandemic on the Reproductive and Child Health Programme of Bihar in India over the 3 months after nationwide Lock down announcement in March 2020? How SARS-CoV-2 Pandemic era does influence RCH Programme, Immunisation,andnbsp; Maternal Health, Family Planning? 30 March 2021, PREPRINT (Version 4) available at Research Square [https://doi.org/10.21203/rs.3.rs-348841/v4]

3. Reid A. The effects of the 1918-1919 influenza pandemic on infant and child health in Derbyshire, Med Hist. 2005 Jan; 49(1):29-54. Doi: 10.1017/s0025727300008279. PMID: 15730129; PMCID: PMC1088249.

4. NHM-Department of Health and Family Welfare, visit at- http://www.nrhmhp.gov.in/content/immunisation

5. The second round of a World Health Organization "pulse survey "visit- https://www.who.int/news/item/23-04-2021-covid-19-continues-to-disrupt-essentialhealth-services-in-90-of-countries

6. World health organisation- Child protection during the period from COVID-19-visit at- https://www.who.int/pmnch/covid-19/toolkits/child/childprotection/en

7. Ministry of Home Affairs, Government of India, visit-https://www.mohfw.gov.in/pdf/Annexure_MHA.pdf

8. Population census of India 2011 visit at -https://www.census2011.co.in/

9. World Health Organisation, 1 September 2020, Departmental news, LAST UPDATE: 12 March 2021, visit-https://www.who.int/news/item/01-09-2020increasing-understanding-of-the-impact-of-covid-19-for-pregnant-women-and-their-babies

10. NFHS-4

11. McClure, Elizabeth M et al. Impact of COVID-19 on maternal and child health, The Lancet Global Health, Volume 8, Issue 10 , e1258 https://www.thelancet.com/journals/langlo/article/PIIS2214-109X(20)30326-0/fulltext

12. Ministry of Health and Family Welfare, government of India- visit-https://www.mohfw.gov.in/index.html

13. Sudhir Anand and Victoria Fan, Human Resources for Health Observer Series Number 16, THE HEALTH WORKFORCE IN INDIA, WHO Library Cataloguingin-Publication Data The health workforce in India, World Health Organization. ISBN 9789241510523 Subject headings are available from WHO institutional repository, visit-https://www.who.int/hrh/resources/16058health_workforce_India.pdf

14. Centre for Disease control and prevention, visit- CDC, Vaccines and Immunizations Home, Basics and Common Questions

15. Antenatal care, April 2021, UNICEF- visit- https://data.unicef.org/topic/maternal-health/antenatal-care

16. World Health Organization (WHO). Mother-Baby Package: A safe motherhood planning guide, WHO, Geneva, WHO/FHE/MSM/94.11 (1994) and others, visit-http://apps.who.int/iris/bitstream/handle/10665/62091/WHO_FHE_FPP_95.11.pdf;jsessionid=596EC4D2EBCE6830C01300A383CF9F46?sequence=1 
17. DR PIYUSH KUMAR. What Impact Have SARS-CoV-2/Covid-19 Pandemic on the Reproductive and Child Health Programme of India over the 3 months after nationwide Lock down announcement in March 2020 -A brief analysis. 25 March 2021, PREPRINT (Version 1) available at Research Square [https://doi.org/10.21203/rs.3.rs-360551/v1]

18. Dr. Piyush Kumar. What Impact Have SARS-CoV-2/Covid-19 Pandemic on the Reproductive and Child Health Programme of Bihar in India over the 3 months after nationwide Lock down announcement in March 2020? How SARS-CoV-2 Pandemic era does influence RCH Programme, Immunisation, andnbsp; Maternal Health? Family Planning, 30 March 2021, PREPRINT (Version 4) available at Research Square [https://doi.org/10.21203/rs.3.rs-348841/v4]

19. Piyush Kumar. What Impact Have SARS-CoV-2/Covid-19 Pandemic on the Reproductive and Child Health Programme of Uttar Pradesh in India over the 3 months after nationwide Lockdown announcement in March 2020 -A brief analysis, 25 March 2021, PREPRINT (Version 1) available at Research Square [https://doi.org/10.21203/rs.3.rs-350287/v1]

20. Kumar P. What Impact Have SARS-CoV-2/Covid-19 Pandemic on the Reproductive and Child Health Programme (Immunization, Maternal Health, Family Planning) of Andhra Pradesh in India over the 3 months after nationwide Lock down announcement in March 2020? Immunization, Maternal Health, Family Planning, OSF Preprints; 2021, Available from: osf.io/dphga

21. DR PIYUSH KUMAR. What Impact Have SARS-CoV-2/Covid-19 Pandemic on the Reproductive and Child Health Programme of India over the 3 months after nationwide Lock down announcement in March 2020 -A brief analysis. 25 March 2021, PREPRINT (Version 1) available at Research Square [https://doi.org/10.21203/rs.3.rs-360551/v1]

22. Timothy Roberton, DrPH ,Emily D Carter, PhD, Victoria B Chou, PhD, Angela R Stegmuller, BSBianca D Jackson, MSPH,Yvonne Tam, MHS, Talata Sawadogo-Lewis, MIPH, Early estimates of the indirect effects of the COVID-19 pandemic on maternal and child mortality in low-income and middle-income countries: a modelling study published by THE LANCET Global Health, https://doi.org/10.1016/S2214-109X(20)30229-1, available athttps://www.thelancet.com/journals/langlo/article/PIIS2214-109X(20)30229-1/fulltext-visited on14/06/2021

\section{Supplementary Files}

This is a list of supplementary files associated with this preprint. Click to download.

- ANNEXURE.docx 